Netherlands Journal of Sea Research

4 (3) : $339-349$ (1969)

\title{
RETINAL STIMULATION AND PATTERN FORMATION IN THE COMMON SOLE SOLEA SOLEA (L.) (PISGES: SOLEIDAE)
}

by

\author{
S. J. DE GROOT*, R. NORDE AND F. J. VERHEIJEN \\ (Laboratory of Comparative Physiology, University of Utrecht, The Netherlands)
}

\section{GONTENTS}

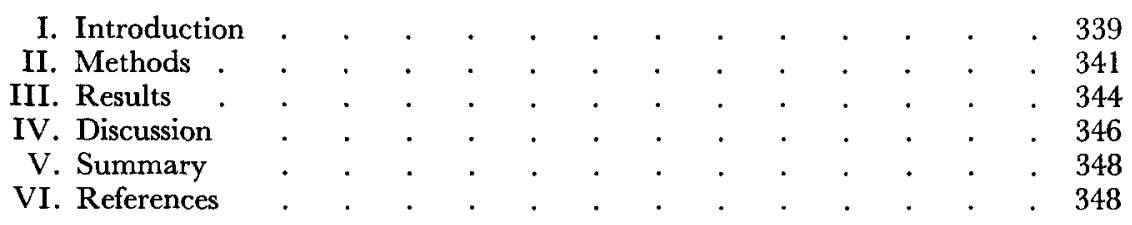

\section{INTRODUGTION}

The powers of a rapid and visually guided adaptive adjustment in shade and pattern to the background in flatfishes have frequently been described. It has been suggested that by rearrangement of pigment within the cells some species can attain even a remarkable resemblance to a chess-board. Sumner (1911) found that especially in the Mediterranean flatfish Rhomboidichthys podas Günther, the white and black figures on the skin were relatively small or large in correspondance with small or large white and black areas on the background. The form of the figures in the skin, however, appeared not to depend upon that of the areas in the background and was essentially of the same irregularity on bottoms containing either black and white squares, stripes, spots or irregular patterns. This has been confirmed by MAST (1916) in the Gulf flounder (Paralichthys albigutta Jordan \& Gilbert), and in the ocellated flounder (Ancylopsetta quadrocellata Gill). Others (PITKIN, 1912; LoEB, 1912 cited by MAST, 1916) were of opinion that the fish can actually reproduce the pattern of the background in the skin. LOEB assumed that the image of the background on the retina would be reproduced in the brain and from there eventually appear as a pattern in the skin. Although such schematic ideas have definitively been abandoned it remains nevertheless far from clear (see e.g., Nikolsky, 1963; WARING, 1963):

* Present address: Netherlands Institute for Fishery Investigations, IJmuiden, The Netherlands. 
a. in how far different species of flatfishes are able to imitate different types of background;

$b$. which causal chain of events connects the retinal stimulation $\mathrm{to}$ the patterns appearing in the skin; and

$c$. what biological significance must be attributed to the patterns produced by different species under different conditions.

The fish seems not to control the result of the adaptation by making visual comparison between the shade and pattern of its own skin and those of the background, because elimination of all of the skin from the field of view of the fish did not interfere with the shade and pattern production in Paralichthys (Mast, 1916). Consequently, the receptoreffector system involved seems to be an open system without visual feedback, not a closed one. This is another argument against the idea that the background pattern would be reproduced exactly in the fish skin.

MAST (1916) and others have demonstrated that the pattern in the skin is influenced only by the background pattern in the near environment. The reason might be that, with the eyes so close to the bottom, the retinal images of bottom patterns at some distance are so strongly distorted that these patterns are hardly perceived by the fish. Another possibility might be that a pattern appears in the skin only when a background pattern stimulates a given localized area of the retina and that a similar stimulation of other areas of the retina is ineffective in this respect.

After elaborate discussions in older work (Sumner, 1911; MAst, 1916; Hewer, 1927, 1931; OsBorn, 1939), recently little attention seems to have been given to the problem. According to PARKER (1948: 171) "the chromatophoral systems of flatfish ... are of a most complicated, perhaps the most complicated type". Under the heading "Chromatophores of Teleosts" in the monograph of Fingerman (1963), flatfish are not dealt with. WARING (1963) restricted the discussions on flatfish to a small appendix $(: 100)$ in which it is admitted that "there is no difficulty, of course, in understanding that nerves to different parts of the skin might convey different messages, but how the retina can initiate these is a complete mystery at present".

More success has been scored with respect to the less complicated phenomenon of shade adaptation. Since von FrIsCH (1911) found that covering of especially the lower halves of the eyes (upper halves of the retinas) of the trout Salmo fario L. led to darkening of the fish, investigators (Sumner, 1933; Butcher, 1938, 1939; Danielson, 1941) do seem to agree that the adaptation of the shade of the fish to the background is made in answer to the relative illumination strengths of the upper and the lower part of the retina, and that these regions of the 
retina are functionally and perhaps also structurally different in this respect.

It has been shown in Xenopus (Amphibia) (Hogben \& Slome, 1936) and in Gasterosteus (Pisces) (Hogben \& Landgrebe, 1940) that the ocular background response determines via the albedo which shade will appear in the skin, by the stimulation ratio of separate receptor groups in localized areas of the retina: a lower (ventral) "B" (black) area stimulated by incident light and an upper (dorsal) "W" (white) area stimulated by light reflected by the background (see also HogBen, 1943).

The main purpose of our investigation was to find out whether in flatfish the production of a pattern in the skin is the result of the stimulation of whatever smaller or larger part of the retina, or whether it depends upon the stimulation of a given localized, and more precisely, a dorsal area. During preliminary experiments with different types of background displayed in the normal position (under the fish), and carried out in order to select the most effective patterns, some data were obtained about the types of pattern that can be produced by the fish. Since the majority of experiments were carried out with the common sole, Solea solea $\mathrm{L}$., the greater part of this report is concerned with this species.

\section{METHODS}

The experiments were carried out in inflatable, circular plastic "instant" basins $100 \mathrm{~cm}$ in diameter and $30 \mathrm{~cm}$ high and filled with seawater of about $16^{\circ} \mathrm{C}$ (Fig. 1). The bottom of each basin consisted of translucent white plastic. During the experiments a basin rested on a plate of glas mounted on supports. Stimulus patterns were displayed on the bottom under the fish, and overhead and all around the fish. The bottom patterns consisted of a sheet of translucent white plastic with painted black patterns or of a sheet of black plastic in which holes had been punched. When either of these sheets was mounted over the white bottom of the basin and illuminated from below, either a black spotted white background or a white spotted black background was displayed. The overhead patterns were produced in the same way; either a white sheet of plastic with painted black patterns or a combination of a punched black sheet with a white sheet were stretched in a circular frame and mounted overhead and-in order to avoid interfering reflections-underwater at such a distance from the bottom that the fish eyes were just midway the ceiling and the background. In this way a given pattern was imaged in the same dimensions and with the same 


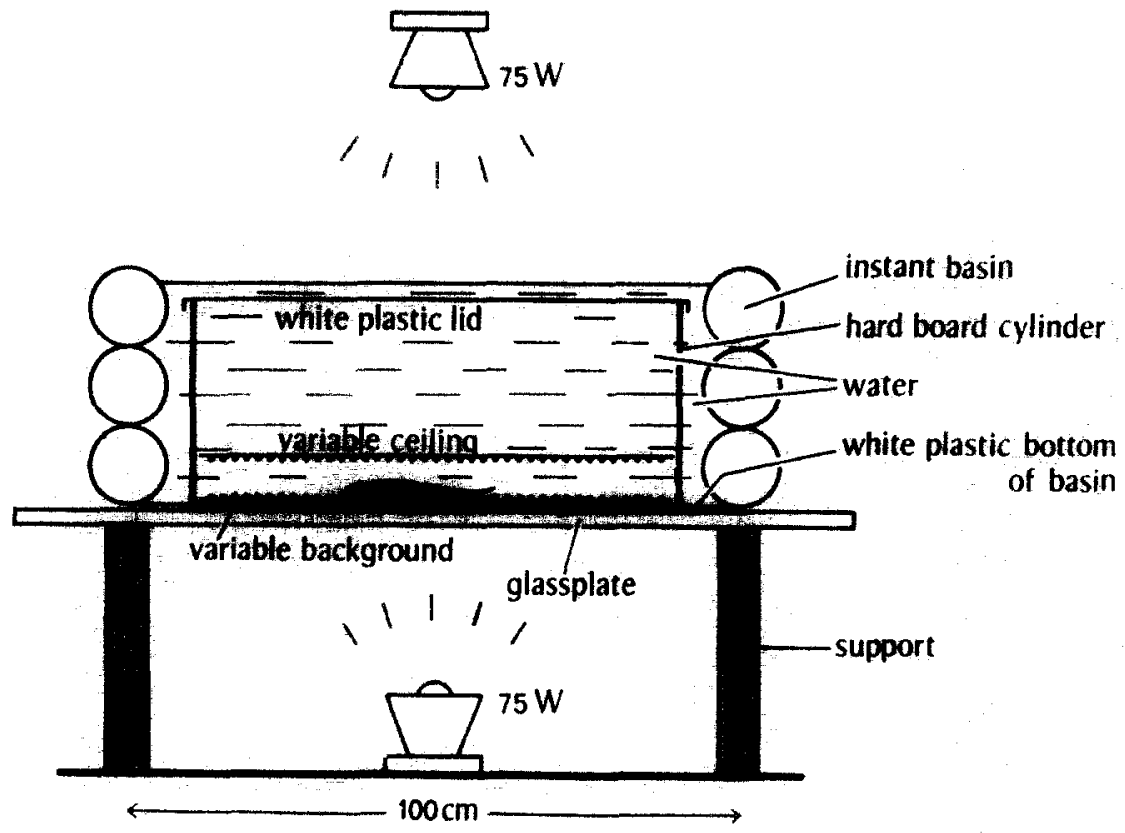

Fig. 1. Diagram of a vertical section through apparatus.
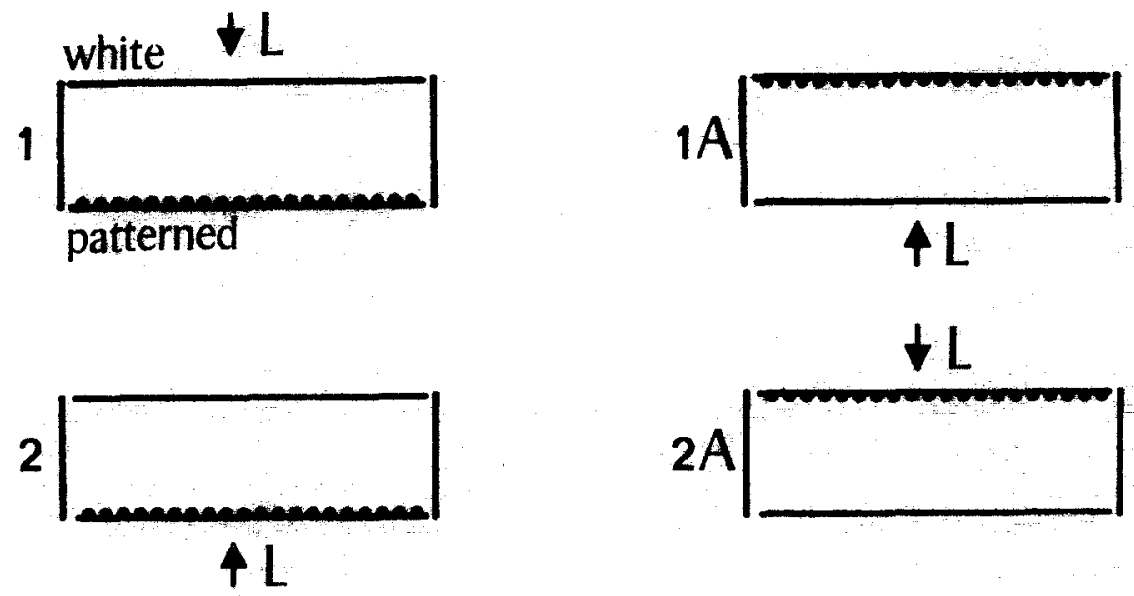

Fig. 2. Diagram of the four stimulus situations: 1. white illuminated ceiling and patterned bottom, 1A. patterned ceiling and white illuminated bottom, 2. white ceiling and illuminated patterned bottom, 2A. illuminated patterned ceiling and white bottom. 
distortions at the retina of the eyes of the fish irrespective as to whether the pattern was displayed over or under the fish. As far as possible matching patterns painted on a hardboard cylinder fitting into the basin were displayed all around the fish. Because of the small distance $( \pm 5 \mathrm{~cm})$ between ceiling and background the cylindrical side wall occupied such a small strip of the visual field that it could hardly be assumed to contribute significantly to the skin pattern. During these experiments the illumination was produced by either of two 75 watt incandescent lamps placed symmetrically with respect to the fish: one at a distance of $50 \mathrm{~cm}$ under the bottom pattern and one $50 \mathrm{~cm}$ above the overhead pattern. The illumination intensity produced in this way was of the order of $30 \mathrm{fc}$.

With the sole the following stimulus situations were tested (Fig. 2):

1. a white ceiling through which the illuminating light penetrated, with a variably patterned bottom;

1A. situation 1 in reverse;

2. a white ceiling with a variably patterned bottom through which the illuminating light penetrated;

2A. situation 2 in reverse.

During preliminary experiments the following backgrounds were tested:

1. uniform white, grey and black backgrounds;

2. a white background irregularly mottled black; and

3. black spotted white and white spotted black backgrounds.

These spotted backgrounds had spot diameters of 4,8 and $10 \mathrm{~mm}$, respectively and mutual spot distances of $5,10,15$ and $80 \mathrm{~mm}$, respectively, and were produced as described above.

In these preliminary experiments the following species were used: the common sole (Solea solea L.), the turbot (Scophthalmus maximus L.), the brill (S. rhombus L.) and the plaice (Pleuronectes platessa L.). These preliminary experiments were carried out at two illumination intensities: a relatively high illumination intensity $( \pm 30 \mathrm{fc})$ produced by a 75 watt incandescent lamp at a distance of $50 \mathrm{~cm}$, and a relatively low illumination intensity of the order of moonlight $( \pm 0.02 \mathrm{fc})$ produced by a 6 volt $/ 0.05$ ampere incandescent lamp at a distance of $200 \mathrm{~cm}$. This low illumination intensity was chosen because the sole (KRUUK, 1963) but also other species of flatfish (VERHEIJEN \& DE GROOT, 1967), are active and out of the sand at night.

Adaptation occurred fairly rapidly: within some minutes, sometimes even within some tens of seconds the first changes in the pigment distribution in the skin pattern could be observed, and adaptation seemed to be completed in 10-20 minutes. This reaction-time is consistent with a predominantly nervous control of the melanophores. 
The patterns finally produced by the fish were observed, and re.. corded photographically one hour after the introduction of a giver stimulus pattern.

\section{RESULTS}

During the preliminary experiments with the sole on uniform grey backgrounds the fish produced a shade that can be evaluated as being adaptive: the shade of the skin matched the shade of the background, and-apart from a very vague and fine-grained speckled appearancehardly any sign of pattern formation was present (Plate Ia). However, when the shade of the background was so dark that it could be called "black" the fish produced a pattern of dark patches and bright white spots (Plate Ib). These white spots are groupings of iridophores exposed to view by the selective aggregation of the melanine in the superjacent melanophores. The biological significance of this pattern and especially that of the white spots is puzzling in the stimulus condition in question. The contrasting white spots do not seem to contribute to concealment, and when they are assumed to have an advertising function it is not clear in which context this advertising would operate. Peculiarly these white spots disappeared when the illumination intensity was reduced to the moonlight level, and reappeared when the original illumination intensity was restored. In all probability visual failure at the low illumination intensity cannot be blamed for the disappearance of the white spots, because the melanophore pattern in answer to a given black-and-white patterned background at this low illumination intensity was indistinguishable from that at the high illumination intensity. Obviously it is not yet clear what features of a stimulus situation do release the display of the white spots. On a uniform black background the brill, the turbot and the plaice also produced conspicuous white spots. Under similar conditions such white spots have been observed in the Gulf flounder (MAsT, 1916) and in the winter flounder (Pseudopleuronectes americanus. Walbaum), the summer flounder (Paralichthys dentatus L.) and the sand dab (Scophthalmus aquosus Mitchill) (HEwer, 1927; OsBorn, 1939).

None of the other species of flatfish used did produce a uniform greyshaded skin in answer to a uniform grey background. The reason is that in all of these species we find (apart from some types of coloured spots produced by definitely distributed groups of chromatophores of different colour left out of consideration here because of the black-andwhite character of the background patterns used in our experiments) black spots of a "non-facultative" character (HEwer, 1931) Such a 
spot, consisting of a higher local concentration of melanophores, can not be made to disappear completely by a different aggregationdispersion condition of the melanophores inside and outside the spot. In the sole such black spots (and the similar coloured spots) are not to be found. The only melanophore pattern this fish can produce is the result of a dispersion of the melanine in a definitely patterned part of the uniformly distributed melanophores. In all probability this "facultative" (HEWER, 1931) but species specific and individually characteristic pattern is based upon a selective innervation of the melanophores in the skin parts belonging to this pattern. Similar facultative dark patches are also found in the other species of flatfish, but there an estimation of the degree in which they give evidence of any adaptation (or, more neutral, reaction) to a patterned background is obscured by the lasting non-facultative spots. Therefore the common sole was chosen for investigations into the relations between the location of the stimulated retinal region and the pattern formation in the skin.

The next step was to find the type of background evoking consistently the best recognizable skin pattern in the sole under natural conditions, i.e., with a patterned bottom illuminated via a white ceiling (stimulus situation 1). It appeared that among the available stimulus patterns (see methods) some gave better results than others in producing a skin pattern of facultative dark patches. Hence the following patterns were used in the stimulus situations $1,1 \mathrm{~A}, 2$, and $2 \mathrm{~A}$ :

$a$. a white background with black dots $4 \mathrm{~mm}$ in diameter and at a mutual distance of $10 \mathrm{~mm}$;

$b$. a white background irregularly mottled black; and

c. a black background with white dots of a diameter and at a mutual distance as in $a$.

At the high illumination intensity 3 soles, total length $16 \mathrm{~cm}, 24 \mathrm{~cm}$, and $33 \mathrm{~cm}$, respectively, were exposed, each 5 times, in each of the 4 stimulus situations $1,1 \mathrm{~A}, 2$, and $2 \mathrm{~A}$, to each of the 3 stimulus patterns $a, b$, and $c$. Clear patterns appeared only in the stimulus situations 1 and 2 , i.e., when a stimulus pattern was displayed on the bottom (Plate II). In the stimulus situations $1 \mathrm{~A}$ and $2 \mathrm{~A}$ (pattern overhead) the fish produced a uniform light grey skin identical to that produced in the preliminary experiments with a uniform white or light grey bottom. It seems therefore clear that in the common sole skin patterns consisting of facultative dark melanophore patches are only produced in answer to stimulation of an upper part of the retina by a stimulus pattern displayed on the bottom. This part of the retina might be designated the "P" (pattern) area. 
The formation of a melanophore pattern in the skin of a flatfish by rearrangement of pigment within the cells may be considered as a definite behavioural pattern elicited by a specific environmental stimulus configuration. Recently there have been elaborate discussions as to whether the filtering mechanism (the "innate releasing mechanism", I.R.M., TinBergen, 1951) which selects the effective stimulus configuration out of the overall environmental stimulus situation is localized peripherally in the receptor or centrally in the nervous system (Marler, 1961; Schleidt, 1962; see also, e.g., Hinde, 1966). It seems that outside the main stream of discussions about this problem among students of animal behaviour, workers on shade and colour adaptation gathered data and developed ideas pertinent to this question.

The darkening melanophore dispersion in trout in answer to darkening of the upper part of the retina voN FRIscH (1911) assumed to be the result of a central process so long as there was little ground to. assume peripheral inhibitory nerves. SUMNER (1933) concluded from similar results in Fundulus that "the chromatophore reactions of fishes are determined by the relative luminosity of the lower and upper portions of the visual field, the former stimulating the chromatophores in a positive sense (i.e., in the direction of conformity), the latter in a negative sense". Butcher (1939) found that only a few receptors in a very small area of the lower region of the eye of Fundulus need to be illuminated by the image of a lamp to induce a darkening of the body. Paling of the body, however, could only be elicited by illuminating retinal receptors in a large area of the upper region of the eye. A lamp so arranged below a fish as to illuminate the upper region of the eye thus failed to induce paling. This seems to be in accordance with the recently studied radiance distribution in the underwater light field under a clear sunny sky (Tyler \& Preisendorfer, 1962). The smaller the angular field of view of the radiance tube used for measuring this radiance distribution, the more the shape of the radiance distribution solid shows a pronounced protrusion produced by large vectors pointing in the direction of the sun. These vectors indicate the high level stimulation of a small area in the lower region of a fish eye that is exposed to the light field in the measuring point. In a measuring point over a light-coloured bottom the radiance distribution solid shows a broad protuberance in its lower half. These vectors indicate the relatively strong stimulation of a large area in the upper region of a fish eye over a light-coloured bottom.

With respect to colour adaptation BUTcher (1938) demonstrated 


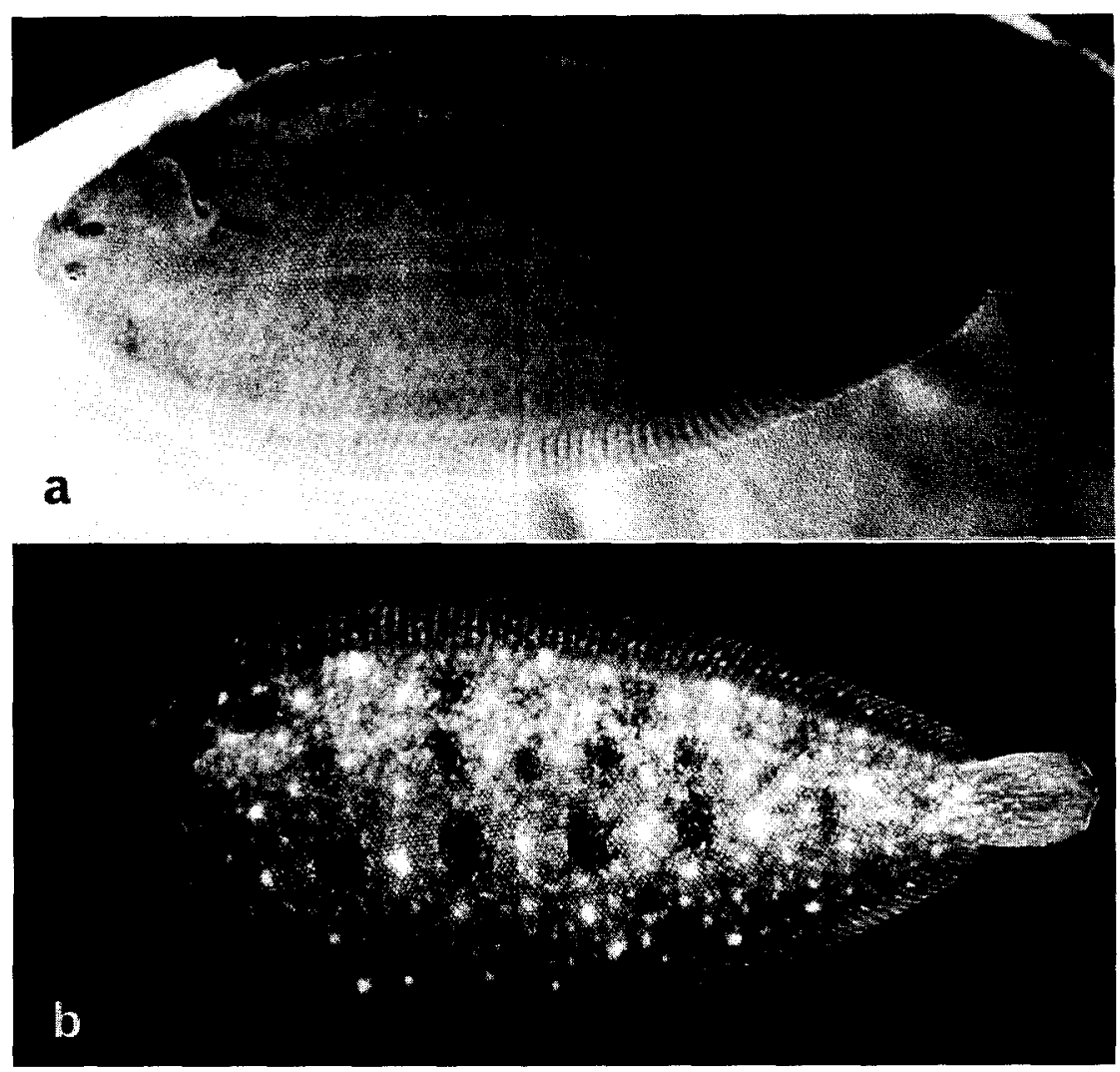

\section{PLATE I}

a. Appearance of a sole over a uniform grey background.

b. Appearance of a sole over a uniform black background. 


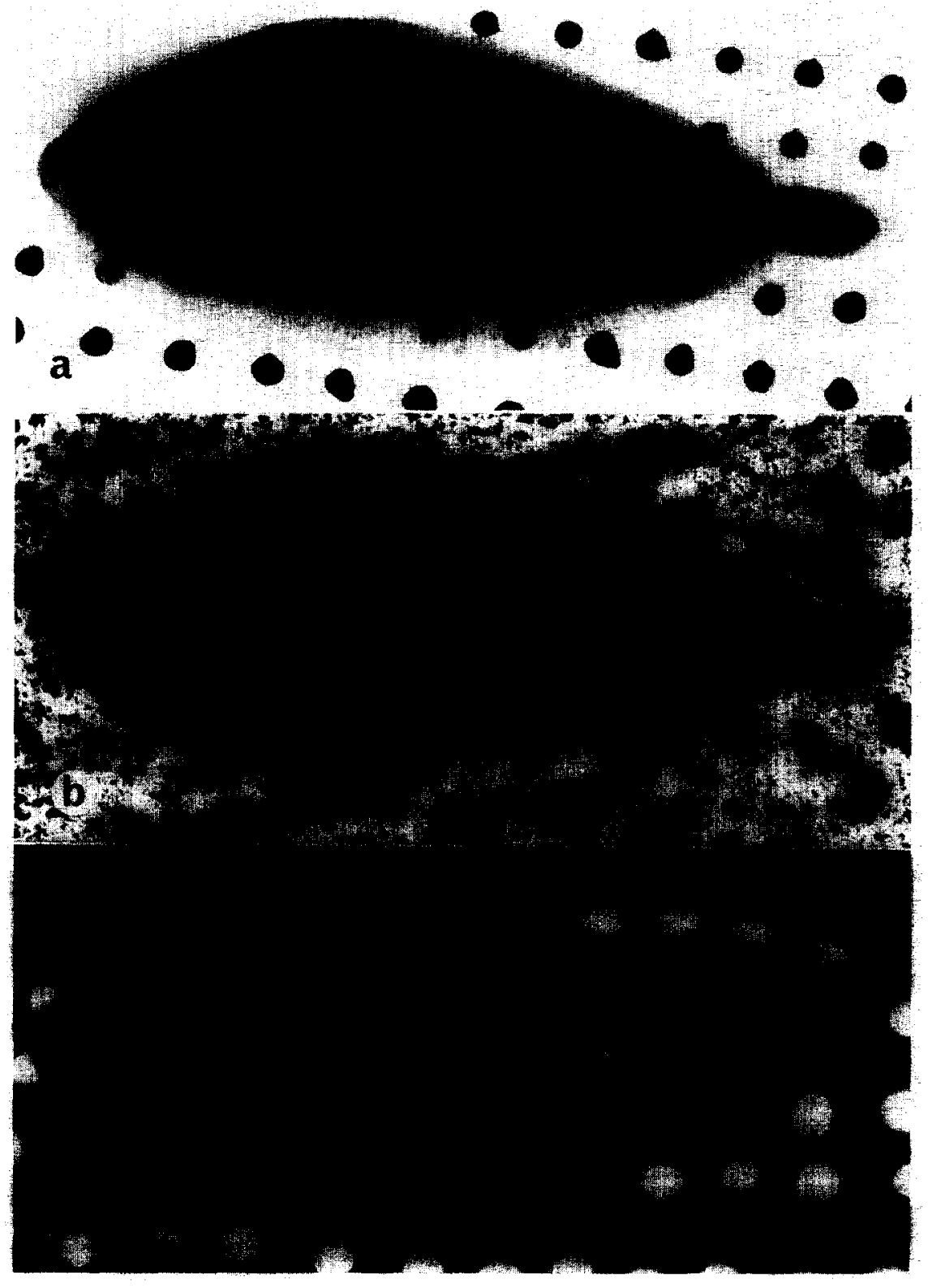

P. I I I I

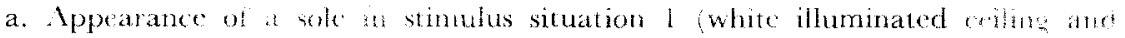
patterned bottom: patten a white background with black dotsi.

b. Appearance of a sole in stimules siluation 1 (white illuminated coifing and pattemed bottom, pattem b white background mottled black).

c. Appearance of a sole in stimulus situation 2 (white ceiling and illuminated pattemed botem? patten e black background with white dots? 
that the xantophores of Fundulus dispers only when yellow light impinges on the upper region of the retina and not when such light falls on the lower region. Although Butcher could differentiate the upper and lower retinal regions histologically, and suggested, for instance, that the exclusive occurrence of single cones in the upper region might be associated with the xantophoric response, he had to admit that shade and color responses may either be due to qualitatively different regions of the retina or to their different central nervous connections. In a review of the relevant literature PARKER (1948) appreciated this problem, as appears from his question (: 154): "Are the retinas of chromatic vertebrates differentiated in such a way as to determine at the outset the particular chromatic response to a given situation or is this determination relegated to a deeper part of the nervous mechanism of these animals?"

Recently the "receptive field" concept has played an important part in electrophysiological studies of the transfer and processing of sensory information in the afferent pathways. These studies indicate that stimulus filtering by encoding of certain features of a stimulus situation may occur-in other words that parts of the releasing mechanism may be located - at any level between the receptor cells with the first relays of the system and the highest nervous centres (for reviews see, e.g., Hinde, 1966; Grossman, 1967). The term "receptive field" was used by HogBen \& LANDGREBe (1940) to delineate two different regions in the retina, a ventral and a central one, which were assumed to be related to the black and to the white background response, and especially in the stickleback Gasterosteus aculeatus L. they tried to relate these regions to the retinal image formation of respectively extra-aqueous objects above and sub-aqueous objects under and around the fish. Moreover, an extreme dorsal region of the retina where no images are formed seemed to be a third region with respect to shade adaptation in this fish, namely a neutral one.

Our experiments showed that in the common sole the formation of melanophore patterns in the skin was released only by the patterned stimulation of an area of the retina which, for this reason, might be termed the "P" (pattern) area. It may be assumed that in the sole this " $P$ " area coincides at least for some part with the " $B$ " area if we assume with WARING (1963: 94) that, although detailed information on " $B$ " and "W" areas in fish is limited to Fundulus (BUTcher, 1938) and Gasterosteus (HoGBen \& LANDGREBE, 1940) "it would be surprising if future work showed other teleosts to be substantially different". The area of the bottom that effects the skin pattern in flatfish, and also the extent of the " $P$ " area of the retina may be supposed to be different according to the species. Sumner (1933) found that the bottom and 
side walls of a container had a different relative influence upon the chromatic responses of different species of flatfish, and he supposed that this might in part be determined by the degree of motility of the eves and the way of life of each species.

In some flatfishes the arrangement of retinal elements has been found to be different in various parts of the retina. The dorsal retina, for instance, might be characterized by distinct element densities or element types (ENGSTRöm \& AHLBERT, 1963). The poor mobility of some retinal elements might be another feature differentiating the dorsal retina from other retinal regions. These local differences in retinomotor movements (Nicol, 1965) might, however, in part be due to the unnatural retinal illumination contrasts that must, in these experiments, almost inevitably have been produced by a lamp over a tank with sides and bottom "dark in hue".

With retinal concepts such as " $B$ " area, " $W$ " area, and the " $P$ " area suggested here, we run the risk to forget that we still have only a very vague idea about the nervous and hormonal mechanisms which regulate shade and pattern (see e.g., WARING, 1963, and, for flatfish, Hewer, 1927; Osborn, 1939). It remains a future task to elucidate how and where in the visual pathway it is decided after light stimuli have impinged upon the " $B$ ", the " $W$ " or the " $P$ " area that the animal will become dark or pale or will show a pattern; how, subsequently, this decision is communicated to the effectors; how the effectors are adequately attuned to this communication; and finally how the resulting reaction contributes to the survival of the individual or the species.

\section{SUMMARY}

In the common sole the formation of a melanophore pattern in the skin by rearrangement of pigment within the cells is released only by a background pattern if this pattern stimulates an area in the upper part of the retina. In harmony with the terms " $B$ " area and " $W$ " area introduced by Hogren \& Stome (1936) for explaining shade adaptation in Xenopus, the term " $\mathrm{P}$ "' (pattern) area is suggested for this retinal area. It is discussed in how far this " $P$ " area gives an indication about the location of the releasing mechanism for the chromatic behaviour studied.

\section{REFERENCES}

Butcher, E. O., 1938. The structure of the retina of Fundulus heteroclitus and the regions of the retina associated with the different chromatophoric responses.- J. exp. Zool. 79: 275-297. 
-, 1939. The illumination of the eye necessary for different melanophoric responses of Fundulus heteroclitus.-Biol. Bull. mar. biol. Lab., Woods Hole 77: 258-267.

Danielson, R. N., 1941. The melanophore response of fishes in relation to contrast in the visual field.-Physiol. Zool. 14: 96-102.

Engström, K. \& I. B. Ahlbert, 1963. Cone type and cone arrangement in the retina of some flatfishes.-Acta zool., Stockh. 44: 119-129.

Fingerman, M., 1963. The control of chromatophores.

FrIsch, K. von, 1911. Beiträge zur Physiologie der Pigmentzellen in der Fischhaut.Pflügers Arch. ges. Physiol. 138: 319-387.

Grossman, S. P., 1967. A textbook of physiological psychology.

Hewer, H. R., 1927. Studies in colour changes in fish. Part II; III; IV.-Phil. Trans R. Soc. (B) 215: 177-200.

-, 1931. Studies in colour changes in fish. Part V.-J. Linn. Soc. (Zool.) 37: 493-512.

Hinde, R. A., 1966. Animal behaviour. A synthesis of ethology and comparative psychology: i-x, 1-534.

Hogren, L., 1943. Chromatic behaviour.-Proc. R. Soc. (B) 131: 111-136.

Hogben, L. \& F. LANDGRebe, 1940. The pigmentary effector system IX. The receptor fields of the teleostean visual response.-Proc. R. Soc. (B) 128: 317-342.

Hogren, L. \& O. Slome, 1936. The pigmentary effector system VIII.-Proc. R. Soc. (B) $120: 158-173$.

KRUUK, H., 1963. Diurnal periodicity in the activity of the common sole, Solea vulgaris Quensel.-Neth. J. Sea Res. 2: 1-28.

MARler, P., 1961. The filtering of external stimuli during instinctive behaviour. In: W. H. Thorpe \& O. L. Zangwill (eds), Current problems of animal behaviour: $150-166$.

MAst, S. O., 1916. Changes in shade, color, and pattern in fishes, and their bearing on the problems of adaptation and behavior, with especial reference to the flounders Paralichthys and Ancylopsetta.-Bull. Bur. Fish., Wash. 34: 173-238.

Nicol, J. A. G., 1965. Retinomotor changes in flatfishes.-J. Fish. Res. Bd Can. 22: $513-520$.

Nikolsky, G. V., 1963. The ecology of fishes: i-xv, 1-352 (Translated by L. Birkett).

Osborn, C. M., 1939. The physiology of color change in flatfishes.-J. exp. Zool. 81: 479-508.

Parker, G. H., 1948. Animal colour changes and their neurohumours: 1-377.

SChleidT, W., 1962. Die historische Entwicklung der Begriffe "Angeborenes auslösendes Schema" und "Angeborener Auslösemechanismus" in der Ethologie.Z. Tierpsychol. 19: 697-722.

Sumner, F. B., 1911. The adjustment of flatfishes to various backgrounds: a study of adaptive color change.-J. exp. Zool. 10: 409-480.

-, 1933. The differing effects of different parts of the visual field upon the chromatophore responses of fishes.-Biol. Bull. mar. biol. Lab., Woods Hole 65: 266-282.

Tinbergen, N., 1951. The study of instinct: i-xii, 1-228.

Tyler, J. E. \& R. W. Preisendorfer, 1962. Light. In: M. N. Hill, (ed.) The Sea, 1, Physical Oceanography: 397-451.

VERHEIJEN, F. J. \& S. J. DE Groot, 1967. Diurnal activity pattern of plaice and flounder (Pleuronectidae) in aquaria.-Neth. J. Sea Res. 3: 315-322.

WARING, H., 1963. Color change mechanisms of cold-blooded vertebrates: i-xii, $1-266$. 